\title{
Ethics in Economics
}

\author{
Gigi Foster ${ }^{1}$
}

\begin{abstract}
This paper presents a slightly modified version of a speech given to the Economic Society of Australia's ACT branch in Canberra in November 2017, as a keynote address at the organisation's annual general meeting. It considers the relationship between economics as a science, and ethical principles both as they guide the actions of practising economists and as they arise in the surrounding social and political context in which economists ply their trade.
\end{abstract}

\section{Introduction}

Thank you very much for inviting me to give tonight's address. In considering what to speak about that would be of most interest and use to the Economic Society of Australia membership here in Canberra, I was inspired by my understanding that my friend Dr Cameron Murray's recent talk to you was very well-received, and by a confluence of recent events and media stories that centre on the theme of ethics. These events and stories focus on behaviour spanning different economic sectorsfrom academia to the government sector to the private sector-and exemplify Game of Mates-style collusive behaviour along networks of favouritism (Murray \& Frijters, 2017), as well as single individuals getting up to various supposed misdeeds all on their own. So tonight, I want to talk about some examples of unethical behaviour, to offer some conceptual musings about ethics from the perspective of economics, and (hopefully of most use to you) to share my views about how to combat behaviour that could be legitimately deemed unethical from the point of view of an economist.

1 School of Economics, University of New South Wales, gigi.foster@unsw.edu.au. 


\section{The ethics underpinning economic science}

A sad and surprising lesson I've learned over my 14 years in Australia is that the reputation of economics in the Australian public discourse is not great. The public does not associate our profession with ethical principles (and we could talk for hours about why that is). The reason I was surprised about this is partly that it's not as true in my home culture of America, and partly that my undergraduate major at Yale was Ethics, Politics and Economics, which is Yale's version of the Oxford PPE (Philosophy, Politics and Ethics) program. This program's very raison d'être rests on the existence of mutual relevance across the three branches of the degree. I was indoctrinated with this mutual relevance so early in my life that it is second nature to me that economic decisions are inevitably bound up with decisions in the moral and political spheres. To my mind, attempting to deny these profound interdependencies is not only foolish, but dangerous.

Some people seem to get confused about the relationship between economics and morality due to the apparent juxtaposition between 'positive' economics on the one hand, and 'normative' economics on the other. Some of this confusion relates to the idea that scientific inquiry should be objective and unbiased. Let me address this latter idea first.

There is no doubt that the ideals of science, both in Australia and internationally, include the notion that a scientist should do everything in his power to maintain objectivity when searching for truth about the world. Whether or not it is justified to draw conclusions on a given subject that are influenced by personal biases, belief or pre-conceptions has been the question that divides 'scientists-as-a-group' from other groups throughout the centuries, from the condemnation of Galileo by the Catholic Church to the Scopes trial.

Economists are fundamentally scientists, to the extent that we seek ever more accurate theories to explain human behaviour. This then implies that there is a moral role for economists-as-a-group in upholding scientific ideals like objectivity, which we promote when we call for transparency in research, for example. Objectivity itself exists as an aspirational ideal, guiding individual economists like an internal lighthouse, constantly keeping us in check to more or less of a degree. We develop that internal lighthouse through years of indoctrination: it's part of what the slog of graduate school is for.

Ultimately, the useful application of economists' pursuit of truth is that it helps us craft better and better policy advice for the stewards of our economies. Hence we are a special variety of social scientist, identified not only by our adherence to scientific ideals like objectivity, but by our deep commitment to the notion of promoting total social welfare. As expressed succinctly by Henry Hazlitt in his classic primer, Economics in One Lesson: 
The art of economics consists in looking not merely at the immediate but at the longer effects of any act or policy; it consists in tracing the consequences of that policy not merely for one group but for all groups (Hazlitt, 1962, p. 17; italics in original).

We draw on a raft of conceptual and analytical tools to advise governments on how to lead society towards a situation in which resources are used best, as defined in this way. Our concept of Pareto efficiency captures neatly the ideal world in which 'the most' has been produced 'for all' with the limited resources available to society.

To say that you wish to see social welfare promoted — or to make any other similar claim about your maximand, such as that you wish to see more social surplus, to get the most welfare bang for a given expended buck, or to move society in the direction of the production possibilities frontier for every productive enterprise-is inherently a moral statement: it is a statement about what matters (and, by implication, what does not matter). As such, a statement like this might be branded as the product of 'normative economics' by those who proudly advertise that they instead promote 'positive economics'.

In my wild youth, I used to proclaim myself a 'positive economist', thinking of the term as denoting my intent to engage in an objective and clear analysis of the facts in front of me, rather than having my analytical efforts muddied by trying to incorporate into my analysis things I couldn't see. The problem with 'positive economics', despite the fact that it sounds more similar to the broader scientific ideal of objectivity, is that if it alone is applied to the analysis of an issue, it cannot deliver a recommendation for any policymaker. Like it or not (and most of us do like it), a primary role for economists in the modern world is to advise policymakers on how to spend their scarce resources. If we are not prepared to make any normative judgement at all—if we content ourselves with merely reporting facts ('inflation has declined', 'we spend $\$ 170$ billion per year on welfare', 'the life expectancy of Indigenous Australians is a decade less than that of non-Indigenous Australians') then we fail in our social role of providing advice. Worse, we open the door for others who are prepared to make normative judgements to interpret our reported facts in whatever way serves the story they would like to tell. Lobby groups can cherrypick the facts we produce to argue for whatever policy they favour. If we content ourselves with being 'positive economists' in this way, are we truly doing a service for our society, or are we merely offering fuel to be added to the flames of whatever lobby group can afford to pay the cleverest storyteller? 


\section{Ethics and the interface of economics and politics}

This is where the interdependence between economics and politics comes to the fore. Every politician perceived to have power to allocate resources is lobbied by competing interests, all telling stories about why allocating more to their preferred cause is the right thing to do-the ethical thing to do. These arguments, in Australia and in many other countries, do contain a whiff of the social welfare maximisation goal that forms the centrepiece of the economist's moral code, but they are made up of other ingredients as well.

Amongst other influences, a nation's culture significantly determines what sorts of arguments are put to its politicians by lobbyists or, in less euphemistic words, how the requests for resources of the various groups that plead for them are packaged. Here in Australia, arguments about protecting 'Aussie battlers' and giving everyone 'a fair go', for example, have been powerful players in our historical political discourse, and not always in the service of maximising the good of all. The trade-offs inherent in making any resource allocation decision-following the principle of opportunity cost, beautifully articulated in Bastiat's parable of the broken window-mean that any allocation represents a compromise amongst the interests of various constituents. While an economist may march into Parliament valiantly with a firm commitment to maximising aggregate social welfare, a few days in the thick of politics will make clear to him that things are not so straightforward. Compromise is everywhere, muddying the ethical principles of the economist. Whose welfare should count the most? How valuable is long-run welfare relative to short-run welfare? Which members of society are the most versus the least deserving of an increase in social surplus flowing to them? The politician's predicament-and that of his economist advisers - is like that of the mother bird staring into the open mouths of her many chicks. There is little clear and economically defensible guidance within economics on the question of optimal distribution: it is aggregate welfare of all that matters, not to whom it flows. So, faced with such open-mouth chicks, the economist must step above the fray and ask: which distribution best promotes the good of all?

Of course, this situation should come as no surprise to economists. One of the fundamental tenets of our discipline, if not the bit of doctrine that we are most famous (or infamous) for, is that people are self-interested and greedy. When resources are on the table, when a pie is to be split, everyone wants a slice. They cannot help themselves. We as economists are prepared to admit this fact of human nature and to move forward in spite of it, rather than-as many other disciplines and professions do-trying to pretend that greed is not of prime importance in motivating people, or even condemning humanity for its greed. We pass no negative judgement upon humanity's greed: in this dimension there is no normativity flowing 
from our discipline. In fact, our entire discipline is based on the notion that given the reality of greed, certain types of structures are best for maximising social welfare. This pursuit of an ultimately normative, moral objective in the face of hard realities that we do not judge per se is what we are engaged in when we argue for the free market. It is an activity that Adam Smith implicitly sanctions in his comment that:

It is not from the benevolence of the butcher, the brewer, or the baker, that we expect our dinner, but from their regard to their own interest. We address ourselves, not to their humanity but to their self-love, and never talk to them of our own necessities, but of their advantages (Smith, 1776: pp. 9-10).

Not all so-called 'freshwater economists' are the demons they are sometimes made out to be: freshwater economics is merely an extremely purist application of the invisible-hand principle to the objective of maximising social welfare.

Even a freshwater economist, with no interest in promoting any distribution of resources for its own sake, would take seriously the recent evidence that more unequal societies grow more slowly (Stiglitz, 2016). This relationship, seemingly driven by mechanisms like weakened aggregate demand and decreased stability when inequality is very high, is the start of a truly pure economic argument in favour of policies to reduce inequality. Rather than trumpeting the notion that inequality is bad per se, the economist would argue that if too much inequality holds all of us back in the long run, then on that moral basis alone we should pursue policies that constrain it.

Of course, not every professed freshwater (or saltwater, for that matter) economist is what one might call a true believer in the moral code of economics. Some economists are seduced into highly partisan camps, where they use the technical and critical thinking skills that the discipline imparts to its apprentices to promote the good not of society as a whole, but of whichever subgroup of society employs them. The demand for our services outside of academia and the public service is high not only because the skills taught in economic programs are applicable to such a wide variety of jobs, but also because economists have a reputation as objective scientists: as students of human behaviour, who will speak the truth independently and without bias. That reputation can be free-ridden upon by those who seek to gain personally by offering information or advice under the banner of economics without themselves truly believing in the moral code of the economist. Rather than economists aiming to promote aggregate social welfare, such people can become economics-trained apologists for their employers, trading in the reputation of the economics profession as if it were a currency, lowering themselves into the basket of those pushing more for their preferred distribution of the pie than for what will maximise its size. But this too is to be expected; after all, there is a lot of money and status that flows from economic consulting and, as we all know, people are greedy-they respond to material incentives. 
A final note on the interface of economics and politics concerns laws. It can be seductive for an economist to think of the existing laws in his society as the exemplification of what is ethical, but this is incorrect. Laws are merely the codification of what a society has decided should be deemed 'right' and 'wrong'. There is nothing absolutist about them: they evolve as social norms evolve, typically slowly, along with the rest of our social institutions. At any given instant, the activities in an economy are supported by a network of current laws (e.g. contract laws) that make it difficult for the parties to a transaction to violate what the society deems to be 'correct behaviour'. A clear and enforced set of laws that support free, cooperative and market-competitive interactions greatly assists societies in maintaining economic efficiency and stability, and some laws at some moments will be strongly in alignment with the promotion of Pareto efficiency. By no means, however, does any of this imply that economists should view any society's current laws as the almighty and absolute judgement about what is and isn't ethical - by the ethical standards of economics, or by anyone else's ethical standards except those of 'this society today, as a whole'. Ultimately, a law, like any other social institution (or even culture), is subject to the economist's moral calculus about whether in the long run it is good for all.

\section{Examples of economically relevant ethics in practice}

I want to share now some examples of ethically laden phenomena that will inform my recommendations about economists' role in identifying and combating unethical behaviour in the course of their practice.

\section{The replicability crisis}

One modern incarnation of the longstanding tension between scientists (including economists) and other members of society can be seen in the increased worldwide focus on the motives of social scientists that has been sparked by the so-called 'replicability crisis'. For those who haven't heard of this 'crisis' - and it has been felt more strongly in psychology than in economics, but it is trickling down into our discipline as well —over the past 10 to 15 years there has been a huge increase in the scrutiny of published results in social science, accompanied by public humiliation (sometimes career-ending) for the scientists responsible for producing results that are found not to be replicable by other scientists, or in other ways found not to have resulted from what are held to be the proper standards of scientific inquiry (e.g. Bartlett, 2017). Fuelled by papers with titles such as 'Why Most Published 
Research Findings are False' (Ioannidis, 2005), this 'crisis' has given birth to all manner of fantastical new jargon, from specification curves to p-hacking to replicability tests and Caliper tests.

This is tricky territory for a well-meaning scientist to navigate because nowhere is it written down exactly what the 'proper standards' of science are. Who determines the content of scientific ideals? Who is the steward of scientific morality? Ultimately, it is 'scientists-as-a-group' who are the custodians of scientific ideals and, for this reason, the replicability crisis contains the essential characteristic of a purge. The ideals that justify the violence of a purge do not come from outside of the group being targeted, as in the case of your stock-standard war, but from within the group itself-akin to the case of the Spanish inquisition or the Salem witch hunt. The violence that accompanies the modern replicability crisis is perpetrated upon individual scientists who are believed to have failed to uphold the ideals of scientists-as-a-group, and it is justified by those same ideals. The vehemence and fanaticism on display are evidence of how crucial those ideals are to the self-image of scientists: if we cannot claim to the rest of society to uphold ideals like objectivity and transparency, then we as a group lose our identity, our sense of common purpose and our coherence as a profession.

The most important ethical dimension of this problem from the economist's perspective, in which aggregate social welfare is the ultimate maximand, is that if science fails in this way then society becomes the larger loser-space is created for people selling 'alternative facts' that have no less credibility than anyone else's (as highlighted in Laine and Taichman, 2017). With no trusted source of independent analysis about a social scientific issue, society loses its common understanding about what problems actually exist, how big they are and what we might do to solve them. We descend into a chaos of conflicting, baseless opinion, and resources are inevitably wasted. No economist would want such a world. Through this lens then, in spite of the suffering of individual scientists (including some who are doubtless fervent adherents to scientific ideals), there is something about the efforts being spawned from the modern replicability crisis that is morally justifiable to an economist.

\section{Norm evolution in groups}

A paper I recently published (Bose et al., forthcoming) tests the malleability of group norms in the presence of what my co-authors and I refer to as 'true believers'. We wanted to know whether the norms of a whole group could be influenced by placing within the group a subset of players who were totally committed to a particular norm-i.e. true believers.

In an experimental lab setting, we asked participants to play simultaneously as giver and receiver in 50 rounds of the Ultimatum Bargaining Game, a standard game used in experimental economics. In this two-player game, the giver is presented 
with an initial 'pie' (say, \$100) and asked to offer the receiver some fraction of the pie (say, $\$ 20$ ), with the remainder to be retained by the giver. The receiver can then choose whether to accept the giver's offer, in which case the proposed division is implemented and the round ends, or to reject the offer, in which case both parties receive nothing and the round ends.

Into this environment we introduced computerised participants, indistinguishable to the human participants from the perspective of any individual player, who were programmed to make and reject offers in accordance with very strict rules-i.e. to adhere strictly to a particular norm about which division of the pie was 'acceptable'.

We found strong evidence that the human players adjusted their offers in the presence of a sufficient number of true believers, whether the norm adhered to was higher or lower than the 'natural' offer rate by human givers, in the absence of computerised participants, of approximately 30 to 40 per cent of the initial endowment. However, the humans behavioural adjustments only arose in treatments where there was punishment-i.e. in which the computerised true believers rejected offers that were too low, even though that rejection ran against their own short-term interest. Merely offering a certain amount each round, but accepting any offer made, resulted in the true believers making lower profits than the human participants and failing to influence humans' offers.

Our findings highlight both the malleability of group norms and the potency of group members who are prepared to enforce norms at a cost to themselves. While in our experiment the different possible norms had no natural ethics-based ordering, we expect a similar dynamic to arise with respect to norms that carry an ethical dimension.

\section{International students and the monetary incentives of universities}

In another paper, this time to do with the university sector, I looked for academic consequences of universities' financial incentives to admit full fee-paying international students (Foster, 2012).

Based on a multi-year set of panel microdata on undergraduate students studying in the business faculties at two Australian universities, I documented lower average performance of international and non-English language speaking students, along with negative spillover effects on both learning and academic standards in their classes. The reason to investigate performance differentials between international and domestic students in the first place was derived from economic logic: with little to no academic oversight of the international student admissions process at most universities, and a strong financial incentive on the part of university leadership to admit international 
students, there was reason to suspect that the ideals academics adhere to-including academic quality and preparation by commencing students-would not be enforced in the admissions process for international students.

This work was widely covered in the media, but also led to the data streams that had supported this research agenda being cut off by the theretofore-participating universities. I attempted to get the Commonwealth Department of Education to sign on to a program of data organisation and access for researchers, so that more such studies could be undertaken for a wider sample of Australian universities, but such an effort was not deemed politically expedient by departmental officials at the time. This is still the sole paper of its ilk to have been published using Australian data.

\section{The formation and stability of exclusive coalitions}

In another working paper, my colleague Ben Greiner and I are using laboratory experiments to explore the ways in which exploitative collusion is supported or suppressed by different communication institutions (Foster \& Greiner, 2017). In our laboratory experiment, groups of five participants play repeated rounds of a game in which they elect a 'dictator' to split the endowment of the whole group. We are interested in what institutional settings catalyse or deter the formation and stability of a 'minimum-winning coalition'-a subset of three of the five players, led by the dictator - to whom the vast majority of the entire group's endowment is allocated. Such exploitative coalitions exclude the other two group members, and in that sense are socially damaging. We test the impact of adding to this election game a 'proposal' stage in which all participants can propose a division of the endowment before the election, although these proposals are not binding (similar to the realworld phenomenon of election campaigns); and, in a separate treatment, the impact of having a binding proposal stage.

We find that the non-binding proposal treatment is best for the establishment and stability of exclusive subgroups. The mechanisms behind this effect are still unclear. However, given the laboratory-based design, these mechanisms clearly relate to communication protocols, thus underscoring the importance of communication norms in generating optimal social outcomes.

\section{How to be an ethical economist}

Armed with these research-founded ideas about norms, politics and communication, I now want to address the following core question for the remainder of my time tonight: what, to an economist, is unethical behaviour, and when and how should we try to stop it? Specifically, in what cases do we as representatives of the profession 
have a moral mandate to call out behaviour as unethical, and what interventions can be effective in stopping such behaviour? The answers I give to these questions here are intended to demonstrate the artistry required to practise economics: notwithstanding the pretty purity of many of our abstractions, making important economic judgements in the messy real world inevitably involves weighing up many different bits of information, based on one's prior knowledge and experience, to work out what is probably best for all in the long run. Such judgements are rarely accompanied by certainty.

Let's begin by considering the example of the replicability crisis. Because of the status one can gain by being seen to be a successful social scientist, there are plenty of examples out there of so-called scientists who are actually not committed to the ideals of objectivity and transparency. In one of my favourite subfields, there are people calling themselves behavioural economists who charge lots of money for advice on how to 'nudge' people to buy goods or services that they do not really need, and others who produce TED talks in which they wave around bottles of allegedly magic 'love potion' (Paul Zak, of the team responsible for Kosfeld et al., 2005). I've already put to you the social welfare argument in favour of maintaining the reputation of social scientists as independent, objective, transparent truthseekers. If you as an economist buy that argument, and if a purge of the ranks is unavoidable in the quest to maintain the reputation of social science, then you will hold your nose and countenance at least some purging efforts, seeing them as part of the periodic self-cleansing of scientists-as-a-group that serves the interest of public welfare. The hope is that, thanks to these efforts, some of the truly bad apples will find themselves no longer part of the group. While that may hurt those bad apples, this would arguably be a worthy sacrifice because it would be outweighed by the benefits thereby accruing to so many others.

However, there is also a danger that the zealotry of these efforts will bring consequences that overshoot the 'Goldilocks point' of adjustment: consequences like heightened compliance checking for all scientists and attempts to very closely monitor exactly what it is that scientists do in their labs and their offices. We have seen a flavour of this attempt already in the increasing administrative burden-for example, in the area of Human Subject Research Ethics compliance protocolsacross Australian universities. The operation of groups in Australia like university ethics boards that have tried to define and take control of 'objectivity' - rather than letting it remain the internal compass for scientists that it is-has resulted in some outcomes that themselves are welfare-reducing (e.g. Paul Frijters' battle with the University of Queensland over his publication of the results of a natural experiment to measure racism on public buses (Mujcic \& Frijters, 2013), which ultimately led to his departure from Australia). In that sense, these groups can be argued to have behaved unethically, from the standpoint of an economist. Because I see this descent 
from purported promotion of ethics to actual unethical behaviour as inevitable given the current human subjects ethics review structure in place at many universities, I have publicly proposed an alternative system (Foster, 2015).

The underlying problem of how to ensure society produces quality scientific research is twofold: first, no monitoring is perfect; and second, monitoring is extremely expensive for society. Scientists are at the end of the day experts, with the knowledge and skills to circumvent any monitoring system if they really want to. Making life difficult for 'good apple' scientists through the establishment of complicated ethical review systems will only hamper scientific progress by frustrating those scientists and taking their time away from actually doing science, following the classic logic of opportunity cost. The ideal state to aim for is one where only those people who are true believers in scientific ideals become scientists, and other people do not, such that only a very low level of external monitoring is necessary.

Naturally, we can never expect to arrive at this ideal state-there will always be a few bad apples in any group - but as with our pursuit of scientific objectivity, we can and should strive for it. Low external monitoring and common ideals to which all group members truly subscribe (which are often, though not always, codified into a system of laws) are characteristics of a healthy group, as they signal stability and the potential for efficient economic exchange on terms that are well-understood and agreed to by all.

In the presence of shared ideals such as tax-paying morale that create efficient internal monitoring of economic players, specific definitions advance neither our understanding of the economic situation nor the outcomes that can be achieved, because of the abstract rather than practical nature of what is actually important. Written rules, templates, forms and other control-oriented mechanisms are merely a by-product: what people hold in their minds to be 'right' is far more important in determining many economic behaviours that we observe in modern society. Through our interactions within groups, a sense of 'right' gradually endogenously forms and then drives the creation of explicit rules-for example, in our legal system.

Taking a final example closer to home, let's consider the welfare fraud and robodebt debacle that Centrelink recently found itself in the middle of (McIlroy, 2017). Taking a big-picture view of this situation, we should expect that some people will indeed abuse the welfare system-we cannot construct a perfect world-and the degree of our outlays of scarce taxpayer money on monitoring and enforcement should be roughly proportional to the degree to which those taxpayers are being ripped off. The total amount of money that welfare fraud is costing the Australian people is a few billion dollars at most, across all individuals committing some form of welfare fraud. An ethical economist considering the right area of monitoring and enforcement in which to spend taxpayer money might note that this figure is very close to the estimated amount of taxation revenue foregone through a much 
smaller number of very rich companies who manage through various mechanisms to avoid paying Australian tax on their operations (Khadem, 2017). I would never claim that welfare fraud is a good thing, but tax fraud by large corporations is just as large a drain on the public purse, with its benefits flowing to a significantly smaller number of richer entities.

The economic problem here is not that corporate tax avoidance or welfare fraud contravene politically correct notions of 'a fair go' for everyone. The problem is that when we as a society allow people or groups to free-ride upon what we produce and thereby get more pie for themselves-in this case, when we allow companies to use our infrastructure and institutions for a lower price per use than the price paid by ordinary Australians, or when we allow people to take more from our social welfare system than what our laws say is due to them-this can destabilise our society and hence, potentially, our longer-run productive capacity. Perceiving our collective wealth and will to be blatantly trampled upon by a particular subgroup pushes us apart from one another, and can ultimately lead to an abandonment of individuals' internal commitment to ideals of tax morale and other internal monitoring that supports a thriving economy, as seen for example in Greece today.

Yet which problem, welfare fraud or corporate tax avoidance, is worse? Any economist knows that the marginal utility of income falls as income rises, so if the choice the economist faced was between spending money to recover $\$ 100$ million in tax avoided by the rich or $\$ 100$ million in tax avoided by the poor, then the most welfare-preserving choice would likely be to spend the resources to recover the tax money from the rich (not to mention that fewer rich people would have to be collected from in order to recover that $\$ 100$ million, cheapening the collection effort). This argument would be only strengthened by the progressive effect of such a policy in a country that already has high inequality, such as the US, as per the findings of Stiglitz (2016).

That we are speaking of corporate rather than personal tax means we must also make a judgement on the longer-term economic effects on everyone of increasing the effective (not actual) tax rate on companies, through changes to their activities in the marketplace provoked by having to pay that tax. Many considerations must be weighed here, including how the tax is to be paid back (a one-off recovery effort? A closing of a loophole in the tax code?), how big a change it would really be for each affected company, and the economic importance of the addition to aggregate demand of poor people who take more money from the welfare system than is their due, compared to the economic importance of the provoked decisions of companies to relocate, invest less, hire fewer workers, and so on. My own personal weighing of the relevant evidence leads me to believe that on net, for most developed economies today and for small to medium changes in tax payable per company, pursuing national-tax-avoiding companies is a more economically ethical choice than pursuing national-welfare-system-defrauding poor people. 
Finally, what can we as economists do about unethical behaviour that we observe in others? Here are a few ideas, once again grounded in my experience and weighing up of the evidence.

First, whenever we are designing schemes to implement regulation, oversight or any sort of monitoring by the 'whole group' (i.e. Australia), we should remember that no monitoring mechanism is perfect. If the stakes are high enough, the target of the monitoring will work out a way to elude it (misreporting, regulatory capture, and so on). For this reason and to minimise the total cost of the monitoring system, limit the costs of compliance for most of those you are targeting. At the same time, to catch the truly bad apples, try to find levers that allow you to reduce the size of the personal gains available to them of doing the wrong thing. Salary caps are one such lever, in cases where observed salaries in a particular level by occupation seem high and politically rather than economically mediated, unable to be clearly linked to performance (which appears to be likely in the case of universities' vicechancellors, for example (Lyons \& Hil, 2018)); others include instituting legal barriers to operating a business in Australia without paying the associated company tax, or making it more difficult for lucrative but total-welfare-draining networks of favouritism to emerge by periodically rotating the personnel doing the regulating.

Second, try to push for adherence to a common set of clearly articulated, pro-social ideals, in order to reduce the need for external monitoring in the first place. This can mean organising and supporting whole-group efforts, like celebrations on Anzac Day or Australia Day that bind us all together as Australians, or the reporting that appears on our tax statements listing where the money is going that is proof positive that we are all interconnected. It can take the form of setting school curriculums that indoctrinate children with a commitment to the critical moral duty of citizens to make choices that support the health of our nation and the welfare of our society.

There are also the tried-and-true methods of promoting social welfare that most people in this room will know. For example, aim for consumer choice in all markets that can support it, including access to a high-quality government provider; design institutions that require people to pay the true value of a public good or a good with externalities; and, in other ways, work towards reducing the personal gains from free-ridership upon public goods.

On a personal note, do not be afraid to speak up when you see what you feel is a contravention of the principle of social welfare maximisation. Reaffirming the morals of the group, being a punishing role model yourself, helps to keep other people in line. There is no moral in the country more defensible than the desire to make all Australians better off in the long run, so you will always find support for that objective, as long as Australia remains strong. Even if your initial belief about the likely welfare effects of particular policy might be wrong, give voice to it anyway, and make space for more people to speak out. The more open debates 
and whistleblowers there are, the fewer costly and unwieldy institutionalised protections there will need to be for them. We need to have more frank discussions about our policy options, and to get deep into the reeds with the pro and con arguments, using objective, scientific arguments and without being side-tracked by defensiveness, bullying or self-righteousness. Is it on balance good for Australia to have the quarantine restrictions that it does? Who are the winners and who are the losers, in the short run and the long run? Is it on balance good or bad for Australia to pursue an industrial policy that supports certain domestic industries? These are economic and political decisions, so there are always going to be trade-offs and compromises, but we should push whenever we can for arguments that are clearly tied to the maximisation of the welfare not just of one segment of Australia, but of Australians-as-a-group. That is a goal that unites all Australians, and as economists it is our moral duty to pursue that goal.

\section{References}

Bartlett, T. (2017). Spoiled Science: How a seemingly innocent blog post led to serious doubts about Cornell's famous food laboratory. Chronicle of Higher Education: Chronicle Review, 17 March. Retrieved from: www.chronicle.com/article/Spoiled-Science/239529

Bose, G., Dechter, E. \& Foster, G. (forthcoming). Behavioral coordination as an individual best-response to punishing role models. Journal of Economic Behavior \& Organization. doi.org/10.1016/j.jebo.2017.03.016

Foster, G. (2012). The impact of international students on measured learning and standards in Australian higher education. Economics of Education Review, 31(5), 587-600. doi.org/ 10.1016/j.econedurev.2012.03.003

Foster, G. (2015). A new model for research ethics reviews. The Conversation, 19 March. Retrieved from: theconversation.com/a-new-model-for-research-ethics-reviews-38296

Foster, G. \& Greiner, B. (2017). The Anatomy of Exclusion: How selfish subgroups form and are maintained in a repeated dictator election game (Working Paper).

Hazlitt, H. (1962). Economics in One Lesson. New York, NY: Manor Books.

Ioannidis, J.P.A. (2005). Why Most Published Research Findings are False. PLOS Medicine 2(8): e124. doi.org/10.1371/journal.pmed.0020124

Khadem, N. (2017). ATO's tax gap figures revealed: $\$ 2.5$ billion missing from corporates, multinationals. Sydney Morning Herald, 10 October. Retrieved from: www.smh.com. $\mathrm{au} /$ business/the-economy/atos-tax-gap-figures-revealed-25-billion-missing-fromcorporates-multinationals-20171010-gyxpkl.html

Kosfeld, M, Heinrichs, M., Zak, P.J., Fischbacher, U. \& Fehr, E. (2005). Oxytocin increases trust in humans. Nature 435(7042), 673. doi.org/10.1038/nature03701 
Laine, C. \& Taichman, D.B. (2017). Alternative Facts Have No Place in Science [Editorial]. Annals of Internal Medicine, 20 June. doi.org/10.7326/M17-0878

Lyons, K. \& Hil, R. (2018). Vice-chancellors' Salaries are Just a Symptom of What's Wrong with Universities. The Conversation, 5 February. Retrieved from: theconversation.com/ vice-chancellors-salaries-are-just-a-symptom-of-whats-wrong-with-universities-90999

McIlroy, T. (2017). 20,000 people sent Centrelink 'robo-debt' notices found to owe less or nothing. Canberra Times, 13 September. Retrieved from: www.canberratimes.com.au/ national/public-service/20000-people-sent-centrelink-robodebt-notices-found-to-oweless-or-nothing-20170912-gyg $8 \mathrm{~mm}$.html

Mujcic, R. \& Frijters, P. (2013). Still Not Allowed on the Bus: It Matters If You're Black or White! (IZA Working Paper No. 7300).

Murray, C. \& Frijters, P. (2017). Game of Mates: How favours bleed the nation. Australia: Cameron Murray and Paul Frijters.

Smith, A. (1776). An Inquiry into the Nature and Causes of the Wealth of Nations (Vol. 1) [ebook version]. Hampshire: Harriman House Ltd. doi.org/10.1093/oseo/instance.00043218

Stiglitz, J. (2016). Inequality and Economic Growth. In M. Jacobs and M. Mazzucato (eds), Rethinking Capitalism. Chichester, West Sussex, UK: Wiley-Blackwell in association with The Political Quarterly. 
This text is taken from Agenda, Volume 25 - Number 1, 2018, edited by William Coleman, published 2018 by ANU Press, The Australian National University, Canberra, Australia.

doi.org/10.22459/AG.25.01.2018.04 